\title{
Atorvastatin and BMD in Coronary Syndrome. Role of Lys656Asn Polymorphism of Leptin Receptor Gene
}

\author{
JOSÉ LUIS PÉREZ-CASTRILLÓN, GEMMA VEGA, LAURA ABAD, ALBERTO SANZ-CANTALAPIEDRA, \\ MANUEl GONZALEZ SAGREDO*, DANIEl DE LUIS* AND ANTONIO DUENAS-LAITA** \\ Internal Medicine Department, Rio Hortega University Hospital, Faculty of Medicine, Valladolid, Spain \\ *Institute of Endocrinology and Nutrition Research Support Unit, Rio Hortega University Hospital, Faculty of Medicine, Valladolid, \\ Spain \\ **Clinical Pharmacology Unit, Río Hortega University Hospital, Valladolid, Spain, RETICEF
}

\begin{abstract}
Objectives. To evaluate the effect of atorvastatin on bone mass and markers of bone remodeling in patients with acute coronary syndrome according to the Lys656Asn leptin receptor gene polymorphism. Methods. Sixty-two patients with acute coronary syndrome were included. Patients were allocated to low and high doses of atorvastatin according to baseline levels of cholesterol and triglycerides and the index of vascular risk and were studied at hospital admission and at 12 months. Cholesterol, triglycerides, total calcium, phosphorus, magnesium, osteocalcin and urinary deoxypyridinoline were determined in all patients at baseline and at 12 months of follow up. Densitometric studies were conducted in the lumbar spine and hip. Patients with a T-score $<-2.5$ were considered osteoporotic. The Lys656Asn leptin receptor gene polymorphism was determined by PCR. Results. Forty-two patients were Lys/Lys homozygotic and 20 Lys/Asn heterozygotic. The prevalence of osteoporosis was $31 \%$ for the Lys/Lys genotype and $27 \%$ for the Lys/Asn genotype with no significant differences between groups. There was a significant increase in bone mineral density in the lumbar spine $(1.117 \pm 0.24$ versus $1.135 \pm 0.24, \mathrm{P}=0.008)$ in patients with the Lys/Lys genotype. Conclusion. Atorvastatin increases lumbar spine bone mineral density only in patients with the Lys/Lys genotype of the Lys656Asn polymorphism.
\end{abstract}

Key words: Atorvastatin, Leptin, Lys658Asn polymorphism, Coronary syndrome

(Endocrine Journal 56: 221-225, 2009)

\begin{abstract}
ATHEROSCLEROSIS and osteoporosis share etiopathogenic mechanisms modulated by the effect of inflammatory mediators, with proinflammatory cytokines being key elements [1]. Inflammation intervenes in both the formation and rupture of atheroma plaque, leading to acute coronary syndrome [2]. Inflammatory cytokines play an important role in the imbalance between bone formation and resorption that leads to the reduced bone mass seen in osteoporosis [3]. In addition, drugs such as statins are effective in both diseases, diminishing vascular events in patients with atherosclerosis and increasing bone mass in those
\end{abstract}

Received: September 25, 2008

Accepted: November 5, 2008

Correspondence to: José Luis PÉREZ-CASTRILLÓN, Hospital Río Hortega, Cardenal Torquemada s/n, 47010 Valladolid, Spain with high levels of cholesterol [4].

Human leptin is a protein of 167 amino acids manufactured in fat cells which is involved in regulating the ingestion and consumption of energy. It intervenes in the regulation of bone mass by means of a central hypothalamic mechanism, exerting a double antagonistic effect on bone formation and resorption through activation of the sympathetic nervous system and the Cocaine Amphetamine Regulated Transcript (CART) [5]. In addition, studies have shown that hyperleptinemia can exert atherogenic effects [6]. In North American patients, elevated leptin levels have been associated with an increased risk of myocardial infarction in both males $(3.16,95 \%$ CI $1.40-7.37)$ and females (3.95, 95\% CI 1.29-12.72) [7].

Leptin exerts its biological effect by bonding with a receptor from the cytokine-receptor family. The leptin 
receptor has been cloned, with 7 SNPs being described in the coding region of the OB-RB receptor. The variability in circulating levels of leptin and its dependency on ingestion may explain the discrepancies found between bone mass and leptin [8,9]. Therefore, analysis of genetic polymorphisms of the leptin system may aid understanding of the association between bone mass, leptin and the response to atorvastatin, independently of the biological variability of leptin levels.

The objective of this study was to evaluate the effect of atorvastatin on bone mass and markers of bone remodeling in patients with acute coronary syndrome according to the Lys656Asn polymorphism of the leptin receptor gene.

\section{Material and Methods}

Patients with acute coronary syndrome diagnosed according to European Society of Cardiology criteria were included. Exclusion criteria were chronic alcohol abuse, neoplasia, chronic renal failure hyper- and hypocalcaemia, hyperparathyroidism and use of drugs modifying bone mineral density (BMD). Patients were allocated to low (10-20 mg) and high doses (40$80 \mathrm{mg}$ ) of atorvastatin according to baseline levels of cholesterol and triglycerides and the index of vascular risk. Patients were classified as low or high risk according to the presence of no or one or more cardiovascular risk factors (smoking, hypertension, diabetes, family history and low HDL-cholesterol) [10]. Measurements were made at baseline and at 12 months of follow up. The study was approved by the hospital ethics committee and written informed consent was obtained from all participants.

Cholesterol, triglycerides, total calcium, phosphorus, magnesium, and alkaline phosphatase were measured using a Hitachi 917 autoanalyzer (Tokyo, Japan). Serum osteocalcin and urinary deoxypyridinoline levels were determined by immunoassay (Immulite DPC, Dipesa, Los Angeles, USA). Densitometric studies were conducted in the lumbar spine (L2-L4) and femoral neck and trochanter using an X-ray densitometer (DXA, Lunar Corporation, Madison, Wisconsin, USA). Patients with a $\mathrm{T}$-score $<-2.5$ were considered osteoporotic.

\section{Genotyping of LEPR gene polymorphism}

Oligonucleotide primers and probes were designed with the Beacon Designer 4.0 (Premier Biosoft International $\left.{ }^{\circledR}, \mathrm{LA}, \mathrm{CA}\right)$. Polymerase chain reaction (PCR) was carried out with $250 \mathrm{ng}$ of genomic DNA, $0.5 \mathrm{uL}$ of each oligonucleotide primer (primer forward: 5'GCA GTT CCT ATG AGA GGA CC-3'; primer reverse: 5'-AAA TTG GGA ATA CCT TCC AAA GT$3^{\prime}$ ), and $0.25 \mathrm{uL}$ of each probe (wild probe: 5'-FamAGT GAC ATT TTT CTC CTT TTT CAT AGT ATC-Tamra-3') and (mutant probe: 5'-Hex-AGT GAC ATT TTT CTC GTT TTT CAT AGT AT- Tamra -3') in a $25 \mathrm{uL}$ final volume (Termociclador iCycler IQ $\left(\right.$ Bio-Rad $\left.^{\circledR}\right)$, Hercules, CA). DNA was denaturated at $95^{\circ} \mathrm{C}$ for $3 \mathrm{~min}$; this was followed by 50 cycles of denaturation at $95^{\circ} \mathrm{C}$ for $15 \mathrm{~s}$, and annealing at $59.3^{\circ}$ for $45 \mathrm{~s}$. PCR were run in a $25 \mathrm{uL}$ final volume containing 12.5 uL of IQTM Supermix (Bio-Rad ${ }^{\circledR}$, Hercules, CA) with hot start Taq DNA polymerase.

The results are expressed as mean \pm standard deviation. Comparisons of the mean were made using the paired t-test (for sample sizes $>30$, homozygotic Lys/ Lys polymorphism patients) and the Mann-Whitney nonparametric $\mathrm{U}$ test (for sample sizes $<30$, heterozygotic Lys/Asn polymorphism patients). Correlations between variables were made using Pearson's $r$ test and Spearman's test.

\section{Results}

Sixty-two patients (35 males and 27 females) with acute coronary syndrome (54 with acute myocardial infarction and 8 with unstable angina) with a mean age of $61 \pm 10$ years were included. Patients were divided into two groups according to the Lys656Asn polymorphism of the leptin receptor gene. Forty-two patients were homozygotic Lys/Lys (69\%) and 20 heterozygotic Lys/Asn (31\%). The prevalence of osteoporosis was $31 \%$ in the Lys/Lys genotype and $27 \%$ in the Lys/ Asn genotype, with no significant differences between the two groups $(p=0.578)$. Baseline parameters (Tables 1 and 2) showed no differences between the two groups. Age $(61 \pm 10$ years vs $62 \pm 9$ years, $p=0.7)$, height $(162 \pm 9 \mathrm{~cm}$ vs $163 \pm 8 \mathrm{~cm}, \mathrm{p}=0.7)$, weight $(74 \pm 12$ vs $75 \pm 9, \mathrm{p}=0.7)$ and BMI $(28 \pm 4$ vs $28 \pm 4, p=0.7)$ were similar in the two groups. No patient had limitations in the activities of daily living 
Table 1. Baseline and 12-months analytical parameters after treatment with atorvastatin according to the genotype expressed.

\begin{tabular}{lccccc}
\hline & \multicolumn{2}{c}{ Homozygote Lys/Lys } & & \multicolumn{2}{c}{ Heterozygote Lys/Asn } \\
\cline { 2 - 5 } \cline { 4 - 5 } & Baseline & 12 -month & & Baseline & 12 -month \\
\hline Cholesterol mg/dl & $173 \pm 41$ & $160 \pm 35^{\mathrm{a}}$ & & $200 \pm 56$ & $160 \pm 30^{\mathrm{e}}$ \\
Triglycerides mg/dl & $142 \pm 70$ & $116 \pm 44^{\mathrm{b}}$ & & $174 \pm 129$ & $145 \pm 94$ \\
Calcium mg/dl & $9.5 \pm 0.5$ & $9.6 \pm 0.5$ & & $9.6 \pm 0.6$ & $9.7 \pm 0.4$ \\
Phosphorus mg/dl & $3.7 \pm 0.6$ & $3.5 \pm 0.6$ & & $3.4 \pm 0.6$ & $3.4 \pm 0.5$ \\
Magnesium mg/dl & $2.2 \pm 0.3$ & $2 \pm 0.3^{\mathrm{c}}$ & & $2.2 \pm 0.2$ & $2 \pm 0.3$ \\
Osteocalcin nmol/l & $3.2 \pm 1.8$ & $1.6 \pm 1.5^{\mathrm{d}}$ & & $2.8 \pm 1.8$ & $0.89 \pm 0.5^{\mathrm{f}}$ \\
Deoxypyridinoline nmol/mmol creatinine & $6.6 \pm 2.7$ & $7.2 \pm 4.7$ & & $6.4 \pm 1.9$ & $5.5 \pm 0.82$ \\
\hline
\end{tabular}

a) $\mathrm{p}=0.028$, b) $\mathrm{p}=0.024$, c) $\mathrm{p}=0.001$, d) $\mathrm{p}=0.0001$, e) $\mathrm{p}=0.001, \mathrm{f}) \mathrm{p}=0.0001$

Table 2. Baseline and 12-month densitometric parameters after treatment with atorvastatin according to the genotype expressed.

\begin{tabular}{|c|c|c|c|c|}
\hline & \multicolumn{2}{|c|}{ Homozygote Lys/Lys } & \multicolumn{2}{|c|}{ Heterozygote Lys/Asn } \\
\hline & Baseline & 12-month & Baseline & 12-month \\
\hline BMD L2-L4 g/ $\mathrm{cm}^{2}$ & $1.117 \pm 0.24$ & $1.135 \pm 0.24^{\mathrm{a}}$ & $1.167 \pm 0.21$ & $1.174 \pm 0.23$ \\
\hline BMD femoral neck $\mathrm{g} / \mathrm{cm}^{2}$ & $0.903 \pm 0.15$ & $0.904 \pm 0.15$ & $0.916 \pm 0.15$ & $0.924 \pm 0.15$ \\
\hline BMD femoral trochanter $\mathrm{g} / \mathrm{cm}^{2}$ & $0.743 \pm 0.25$ & $0.753 \pm 0.22$ & $0.726 \pm 0.31$ & $0.755 \pm 0.27$ \\
\hline
\end{tabular}

a) $\mathrm{p}=0.008$

during the 12-month follow up. Only one patient had a vertebral fracture. There were no differences between the two groups in the drugs received. Analysis of the response to atorvastatin showed reduced cholesterol and triglyceride levels in the Lys/Lys group and only reduced cholesterol in the Lys/Asn group. The reduction in osteocalcin was similar in the two groups (Table 1).

There were differences in the response of bone mass to avortastatin according to the genotype. In the lumbar spine (L2-L4), there was a statistically significant increase in BMD $(1.117 \pm 0.24$ versus $1.135 \pm 0.24$, $\mathrm{p}=0.008$ ) in patients with the Lys/Lys genotype, but not in those with the Lys/Asn genotype. After adjustment for age and sex (z-score- $0.062 \pm 1.89$ versus $0.149 \pm 1.51, p=0.001)$ an increase in BMD of $1.9 \% \pm 4.2 \%$ in Lys/Lys patients and a reduction of $0.1 \% \pm 0.1 \%$ in Lys/Ans patients was observed, with the difference being significant ( $p=0.005$ ).

Fig. 1 shows the changes in BMD for each patient according to the polymorphism expressed. No changes in BMD were found in either group in the femoral neck or trochanter (Table 2). There were no differences in the response of bone mass to atorvastatin according to the drug dose (initial, $1.192 \pm 0.22$ vs $1.144 \pm 0.23, \mathrm{p}=0.4$ and final, $1.213 \pm 0.22$ vs $1.153 \pm 0.23, \mathrm{p}=0.4)$.

\section{Discussion}

Our results show that the Lys656Asn polymorphism of the leptin receptor gene does not influence BMD in patients with acute coronary syndrome. The incidence of osteoporosis was similar in the two genotypes analyzed. However, we found a different response to atorvastatin according to the genotype. Patients with the Lys/Lys genotype showed increased BMD in the lumbar spine, while those with the Lys/Asn genotype did not. In the polymorphism analysed, lysine was replaced by arginine in codon 656 of exon 14. This modification in the extracellular domain of the receptor can change its charge, with functional consequences affecting bonding of the receptor with leptin.

Few studies have analyzed variations in bone mass between the polymorphisms of the leptin receptor. The results differ, with some studies finding an association with the substitution of adenine by guanine in position 668 of exon 6 (Gln223Arg) and changes in bone mass and an increase in vertebral fractures [11, 12], but no modifications of bone density with the Lys656Asn polymorphism. These results are similar to those of our study. We found no baseline differences between the two groups studied. A reduction in osteocalcin was observed in both polymorphisms. Osteocalcin is a small non-collagenous protein synthe- 


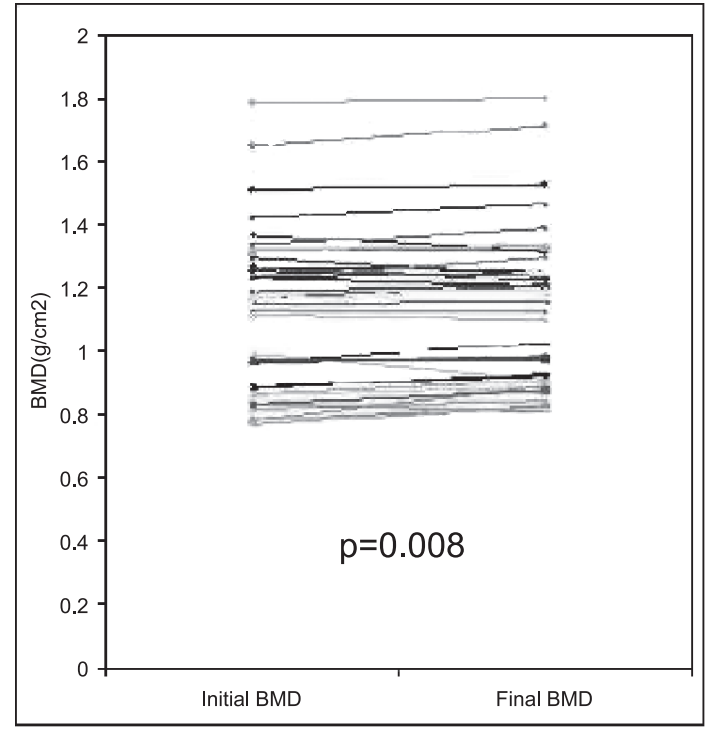

Homozygote lys/lys

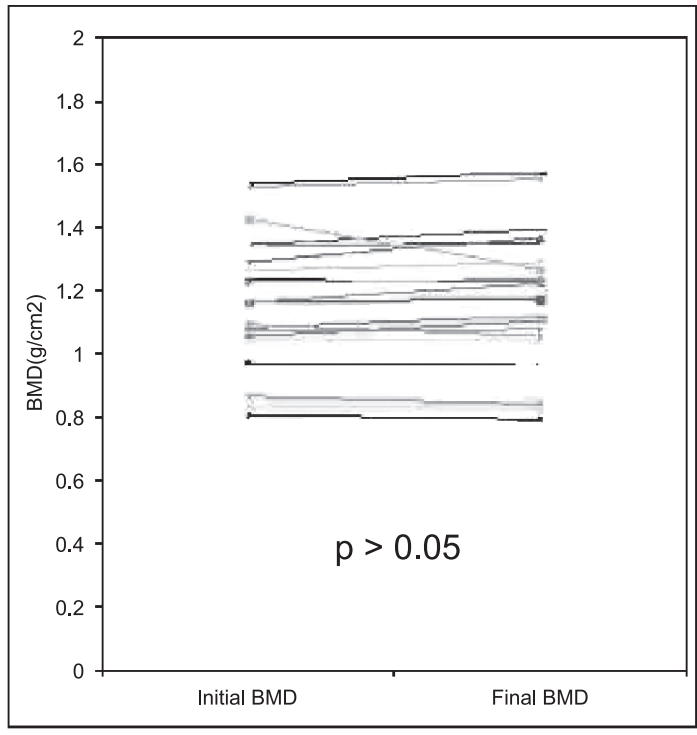

Heterozygote lys/asn

Fig. 1. Individual changes of BMD in homozygote lys/lys and heterozygote lys/asn patients.

sized by matrix osteoblasts. It is considered a sensitive index of osteoblastic activity and a marker of bone formation. However, the proteolytic fragments of this peptide could be released during bone matrix resorption [13] and thus it can be considered a marker of bone turnover. A reduction in remodeling increases BMD. However, the treatment response was different. It should be remembered that the polymorphism analysed is not associated with changes in leptin levels but rather causes leptin resistance [14]. Atorvastatin may modify this situation and the increase in BMD may be related to an anabolic action of leptin.

This differing response may be explained by the interaction between leptin and the enzyme, HMG-CoA reductase. Atorvastatin acts at the level of HMG-CoA reductase, a hepatic enzyme which limits endogenous cholesterol synthesis. Experimental models have shown that a defective leptin signal causes a loss of the circadian rhythm of the enzyme with an increase in hepatic enzyme activity and a reduction in 27-hydroxylase cholesterol and 7-alpha-reductase cholesterol [15]. The mechanism which produces this increase in activity is a reduction of the activity of the enzyme, AMP-protein kinase [16, 17]. This difference could explain modification of the response to the statin.
Few studies have evaluated the response to statins according to leptin polymorphisms. TakahashiYasuno et al. [18] analysed a different statin, sinvastatin, and a different polymorphism. The role of other polymorphisms adjacent to that analysed cannot be discarded and should be further studied. The response was only observed in the lumbar spine and not in the hip. This may be because the hip bone is metabolically less active, with a poorer response to anticatabolic drugs, meaning that greater antiresorptive power would be needed and that the effect of atorvastatin is small.

The main limitation of our study was the sample size, even though the study population was uniform. In addition, we did not measure leptin levels. Another limitation is the absence of an objective method for assessing therapeutic compliance, which was assessed using the information provided by the patient at the last visit.

In conclusion, in patients with acute coronary syndrome, atorvastatin increases lumbar spine bone mineral density only in patients with the Lys/Lys genotype of the Lys/656/Asn polymorphism of the leptin receptor gene. 


\section{References}

1. Perez-Castrillón JL, De Luis D, Dueñas-Laita A (2008) Atherosclerosis and osteoporosis. Minerva Med 99: 45-54.

2. Hansson GK (2005) Inflammation, atherosclerosis, and coronary artery disease. $N$ Engl J Med 352:1685-1695.

3. Pacifici R (1996) Estrogen, cytokines and pathogenesis of postmenopausal osteoporosis. J Bone Miner Res 11: 1043-1051.

4. Pérez Castrillón JL, Abad L, Vega G, SanzCantalapiedra A, Sanchez S, Hernandez G, et al. (2006) Effects of statins on bone markers, bone mineral density and fractures. Possible role in osteoporosis treatment. Cur Pharm Anal 2: 161-168.

5. Karsenty G (2006) Convergence between bone and energy homeostases: review leptin regulation of bone mass. Cell Metabolism 4: 341-348.

6. Beltowski J (2006) Leptin and atherosclerosis. Atherosclerosis 189: 47-60.

7. Sierra-Johnson J, Romero-Corral A, Lopez-Jimenez F, Sert Kuniyoishi FH, Wolk R, Somers VK (2007) Relation of increased leptin concentration to history of myocardial infarction and stroke in the US population. Am J Cardiol 100: 234-239.

8. Yamauchi M, Sugimoto T, Yamaguchi T, Nakaoka D, Kanzawa M, Yano S, Ozuru R, Sugishita T, Chihara K (2001) Plasma leptin concentrations are associated with bone mineral density and the presence of vertebral fractures in postmenopausal women. Clin Endocrinol 55: 341-347.

9. Weiss L, Barrett-Connor E, Von Muhlen D, Clark P (2006) Leptin predicts BMD and one resorption in older women but not older men: the Rancho -Bernardo Study. J Bone Miner Res 21: 758-764.

10. Grundy SM, Cleeman JI, Merz CN, Brewer HB, Clark LT, Hunninghake DB, et al. (2004) Implications of recent clinical trials for the National Cholesterol Education Program Adult Treatment Panel III guidelines. Circulation 110: 227-239.
11. Hamrick MW, Ferrari SL (2008) Leptin and the sympathetic connection of fat to bone. Osteoporos Int 19:905-912.

12. Fairbrother UL, Tanko LB, Walley AJ, Christiansen C, Froguel P, Blakemore AIF (2007) Leptin receptor genotype at Gln223Arg is associated with body composition, BMD, and vertebral fracture in postmenopausal Danish women. J Bone Miner Res 22: 544-550.

13. Seibel MJ (2005) Biochemical markers of bone turnover: Part I. Biochemistry and variability. Clin Biochem Rev 26: 97-122.

14. De Luis Roman D, Aller de la Fuente R, Gonzalez Sagrado M, Izaola O, Conde Vicente R (2006) Leptin receptor Lys656Asn polymorphism is associated with decreased leptin response and weight loss secondary to a lifestyle modification in obese patients. Arch Med Res 37: 854-859.

15. VanPatten S, Ranginami N, Shefer S, Nguyen LB, Rossetti L, Cohen DE (2001) Impaired biliary lipid secretion in obese Zucker rats: leptin promotes hepatic cholesterol clearance. Am J Physiol Gastrointest. Liver Physiol 281: G393-G404.

16. Minokoshi Y, Kim YB, Peroni OD, Fryer LG, Müller C, Carling D, et al. (2002) Leptin stimulates fatty-acid oxidation by activating AMP-activated protein kinase. Nature 415: 339-343.

17. Ferrer A, Caelles C, Massot N, Hegardt FG (1985) Activation of rat liver cytosolic 3-hydroxy-3-methylglutaryl coenzyme A reductase kinase by adenosine 5'monophosphate. Biochem Biophys Res Commun 132: 497-504.

18. Takahashi-Yasuno A, Masuzaki H, Miyawaki T, Ogawa Y, Matsuoka N, Hayashi T, et al. (2003) Leptin receptor polymorphism is associated with serum lipid levels and impairment of cholesterol lowering effect by simvastatin in Japanese men. Diabet Res Clin Pract 62: 169-175. 